\title{
Formulação de rações para poedeiras com base em aminoácidos totais e digestíveis utilizando diferentes estimativas da composição de aminoácidos em alimentos ${ }^{1}$
}

\author{
Rosemeire da Silva Filardi ${ }^{2}$, Elenice Maria Casartelli ${ }^{3}$, Otto Mack Junqueira ${ }^{4}$, Antonio Carlos \\ de Laurentiz ${ }^{5}$, Vinícius Assuena ${ }^{6}$, Eliana Aparecida Rodrigues ${ }^{5}$ \\ 1 Projeto financiado pela FAPESP (processo: No. 03/02648-6). \\ 2 Pós-Doutoranda - Faculdade de Ciências Agrárias e Veterinárias de Jaboticabal (FCAVJ-UNESP) - Rod. Prof. Paulo Donato Castellane \\ $s / n$. Jaboticabal - SP. Autor para correspondência. \\ ${ }^{3}$ Doutoranda em Zootecnia-FCAVJ-UNESP. \\ ${ }^{4}$ Departamento de Zootecnia da FCAVJ-UNESP. \\ ${ }^{5}$ Doutor em Zootecnia pela FCAVJ-UNESP. \\ ${ }^{6}$ Mestrando em Zootecnia-FCAVJ-UNESP.
}

RESUMO - Foram utilizadas poedeiras comerciais com 27 semanas de idade, distribuídas em delineamento inteiramente ao acaso, em esquema fatorial $3 \times 3$, com três repetições de seis aves por tratamento. Os fatores consistiram de três métodos de estimativa da composição de aminoácidos em ingredientes (tabelas brasileiras, equações de predição e fator para correção de aminoácido em função do teor de proteína do ingrediente) e três recomendações de aminoácidos, sendo duas de aminoácidos digestíveis e uma de aminoácidos totais. Os métodos de estimativa da composição de aminoácidos nos ingredientes afetaram apenas a conversão alimentar e a espessura de casca, que apresentaram os melhores resultados com a utilização das tabelas brasileiras. Embora as recomendações de aminoácidos tenham determinado diferenças em todos os parâmetros de desempenho, não afetaram a qualidade dos ovos. O desempenho das aves foi prejudicado pelos níveis de aminoácidos digestíveis, entretanto, ambas as recomendações promoveram desempenho semelhante e inferior ao de aminoácidos totais. O pior desempenho das aves alimentadas com as rações formuladas com aminoácidos digestíveis pode ser atribuído à deficiência em nitrogênio para a síntese de aminoácidos não-essenciais, visto que o nível protéico foi reduzido $(12,5 \%$ PB), ou ainda à deficiência nos aminoácidos arginina, histidina, isoleucina, leucina e valina, cujos requerimentos mínimos não foram considerados na formulação das rações.

Palavras-chave: aminoácidos digestíveis, aminoácidos totais, baixa proteína, custo de produção, equações de predição

\section{Diet formulation based on the total and digestible amino acids and different estimates of amino acid ingredient composition, for laying hens}

\begin{abstract}
Twenty-seven week-old commercial laying hens were allotted to a completely randomized design with a $3 \times 3$ factorial arrangement with three replicates of six birds per treatment. The factors consisted of hree methods for estimatingamino acid ingredient composition (Brazilian tables, prediction equations and factor for correcting amino acid in function of ingredient protein level) and three amino acid recommendations, being two for digestible amino acids and one for total amino acid. Methods for estimation amino acid ingredients composition had effect only on feed conversion and shell thickness. The better results were found by using Brazilian tables for calculating amino acid values of ingredients used in diet formulation. Although, amino acid recommendations affected all performance parameters, they did not affect egg quality. Bird performance was prejudiced by digestible amino acid recommendation. The two digestible amino acid recommendations led to similar performances, which were lower than those reached after following total amino acid recommendation. The worst performance observed in birds fed diets balanced according to digestible amino acid recommendations might be a consequence of nitrogen lacking for synthesis of non essential amino acids, once protein level was reduced $(12.5 \% \mathrm{CP})$, and also explained by the deficiency in arginine, histidine, isoleucine, leucine and valine because their requirements were not considered in the diet formulation.
\end{abstract}

Key Words: digestible amino acids, low protein, prediction equations, production cost, total amino acids

\section{Introdução}

Grande parte dos custos com alimentação de aves está associada ao atendimento das exigências de aminoácidos, o que torna esses nutrientes de grande importância na escolha de ingredientes para rações. Embora o conhecimento da composição de aminoácidos seja importante na formulação de rações, a utilização desta informação é limitada, visto que a 
quantidade de aminoácidos digestíveis no alimento é normalmente menor que a dos aminoácidos totais.

Segundo Dale (1992), na formulação de rações com base nos valores de aminoácidos totais, as possibilidades de erros são grandes, pois os aminoácidos sintéticos e aqueles presentes no alimento possuem os mesmos valores relativos, menosprezando-se o valor da fonte sintética, que geralmente possui disponibilidade de aproximadamente $100 \%$, enquanto, nas fontes naturais, a disponibilidade é inferior. Além disso, quando se substitui o farelo de soja por ingredientes alternativos, como a farinha de penas, pode haver comprometimento no aporte de aminoácidos, uma vez que a disponibilidade de aminoácidos da farinha de penas é comprovadamente inferior à do farelo de soja.

O primeiro passo para se adotar o sistema de aminoácidos digestíveis na formulação de rações é a obtenção dos valores de aminoácidos digestíveis dos ingredientes, alguns descritos em tabelas de composição de alimentos (NRC, 1994; Degussa, 1996; Rostagno et al., 2000). Entretanto, sabe-se que a composição varia de acordo com uma série de fatores, entre eles o método de estimativa do nutriente. De acordo com Sibbald (1987), os métodos de estimativa da composição dos aminoácidos nos ingredientes variam em precisão; alguns são indiretos e outros diretos, mas podem satisfazer necessidades específicas se suas limitações foram reconhecidas e compreendidas.

As metodologias e os aparelhos utilizados para análise de aminoácidos são bastante complexos e de custo elevado, o que dificulta a análise de todas as amostras.

De acordo com Swick (1992), o conteúdo de aminoácidos dos alimentos pode ser estimado por meio da utilização de equações de regressão múltiplas baseadas na composição centesimal e de equações de regressão linear com base no valor de PB e MS ou pelo uso de fator para correção. Pelo fator de correção, o valor de PB é determinado na amostra e dividido pelo valor de PB do alimento apresentado na tabela de composição adotada como referência, estimando-se os valores de aminoácidos da amostra pela multiplicação dos valores de aminoácidos da tabela de composição pela taxa obtida.

A determinação da digestibilidade de aminoácidos tem sido feita por meio de métodos in vitro, in vivo ou de espectroscopia de refletância próximo do infravermelho(NIRs). A digestibilidade de aminoácidos em aves pode ser estimada de várias formas, mas nos ensaios geralmente são utilizados galos adultos cecectomizados (Rostagno et al., 1995).

Os coeficientes de digestibilidade de aminoácidos dos ingredientes mais utilizados em rações para aves comprovam que a digestibilidade dos aminoácidos, na maioria dos ingredientes, é inferior a 100\% (Rostagno et al., 1995; Rostagno et al., 2000). Portanto, rações formuladas com base em aminoácidos digestíveis atenderiam mais eficientemente que aquelas formuladas com base na concentração total de aminoácidos (Rostagno et al., 1995; Wang \& Parsons, 1998; Doulglas \& Parsons, 1999; Araújo et al., 2004; Bellaver et al., 2001; Maiorka et al., 2004).

São poucos os estudos nos quais é comparado o desempenho de poedeiras comerciais recebendo rações formuladas com base em aminoácidos totais e digestíveis (Wangen, 1993; Farrell et al., 1999; Kathun et al., 1999; Silva et al., 2000; Casartelli, 2004). Entretanto, os resultados obtidos nestes estudos são muito conflitantes quanto ao desempenho produtivo das aves e à qualidade dos ovos, indicando a necessidade de mais investigações sobre a utilização de diferentes recomendações de aminoácidos totais e digestíveis para poedeiras comerciais. Os resultados descritos por Wangen (1993), Farrell et al. (1999) e Kathun et al. (1999) indicam que a formulação com base em aminoácidos digestíveis é mais vantajosa que aquela com base em aminoácidos totais, principalmente quando se utilizam ingredientes alternativos. Os resultados relatados por Silva et al. (2000) e Casartelli (2004), no entanto, não confirmam essa vantagem.

Este estudo foi realizado com os objetivos de avaliar diferentes formas de estimativa da composição em aminoácidos totais e digestíveis de ingredientes e analisar diferentes recomendações de aminoácidos totais e digestíveis para poedeiras comerciais.

\section{Material e Métodos}

Foram utilizadas 162 poedeiras comerciais Lohmann LSL de 27 semanas de idade, distribuídas em um delineamento inteiramente ao acaso, em esquema fatorial, com três métodos de estimativas da composição de aminoácidos em ingredientes, três diferentes recomendações de aminoácidos nas rações e três repetições de seis aves por tratamento. Os métodos para obtenção da composição em aminoácidos dos ingredientes utilizados foram:

Método 1 - utilização dos teores de aminoácidos totais e digestíveis especificados nas Tabelas Brasileiras de Composição de Alimentos (Rostagno et al., 2000);

Método 2 - utilização dos teores de PB e MS determinados em laboratório nas equações de regressão das Tabelas da Degussa (Degussa Feed Additives, 1996). O teor de aminoácido digestível foi calculado utilizando-se os coeficientes constantes nas tabelas da Degussa (1997); 
Método 3 - utilização do fator de aminoácidos para estimativa da composição de aminoácidos totais, considerando a composição em PB e aminoácidos totais dos alimentos preconizada nas Tabelas Brasileiras (Rostagno et al., 2000) e os coeficientes de digestibilidade:

Fator aminoácido $(\mathrm{FAA})=\quad \mathrm{PB}$ determinada $(\%)$ PB (\%) na tabela de referência

Aminoácido estimado (\%) =FAA $x$ teor do aminoácido na tabela referência (\%)

Para as recomendações de aminoácidos, foram utilizadas duas fontes para aminoácidos digestíveis (Degussa, 1997; Rostagno et al., 2000) e uma para aminoácidos totais (Rostagno et al., 2000).

Antes da formulação das rações experimentais, foi realizada a análise dos teores de PB e MS dos ingredientes. Os dados foram aplicados para estimativa da composição em aminoácidos dos alimentos por meio de equações ou do fator de correção para aminoácidos (Tabela 1).

Foram utilizadas rações isocalóricas $(2.850 \mathrm{kcal} \mathrm{EM} / \mathrm{kg})$, isocálcicas $(3,65 \% \mathrm{Ca})$ e isofosfóricas $(0,34 \%$ fósforo disponível), com nível de proteína e aminoácidos variando conforme a recomendação utilizada (Tabela 2). Na formulação das rações com base nos aminoácidos digestíveis, foi considerado o atendimento às exigências para esses nutrientes desconsiderando as recomendações de PB. Entretanto, entre as duas recomendações de aminoácidos digestíveis, o nível protéico foi o mesmo. Na formulação de ração, foram consideradas apenas as exigências de lisina, metionina, metionina + cistina, treonina e triptofano. Para o atendimento às exigências dos demais aminoácidos essenciais, sem a alteração nos níveis protéicos das rações, seria necessária a utilização de aminoácidos sintéticos (L-arginina, L-isoleucina e outros) ainda não utilizados pela indústria, em razão do alto custo de comercialização desses aminoácidos.

O desempenho das aves foi avaliado por meio do consumo de ração, da produção e do peso dos ovos e da conversão alimentar em cinco ciclos de 21 dias. A qualidade dos ovos foi avaliada durante os três últimos dias de cada ciclo a partir do peso médio do ovo, da espessura de casca, da Unidade Haugh e da gravidade específica.

Os custos das rações foram determinados considerando-se a composição das rações e o preço dos ingredientes obtidos em agosto de 2004. Para fins de análise estatística, foram feitas médias do custo da ração em função do método de estimativa da composição de aminoácidos dos ingredientes e da recomendação de aminoácidos. O custo de produção foi avaliado pelo custo da ração, pois todos os custos foram iguais entre os tratamentos, sendo o custo da ração usado para avaliar o custo mensal por ave e o custo por quilograma e por dúzia de ovos.

Os dados obtidos neste experimento foram submetidos à análise de variância por meio do procedimento General Linear Model (GLM), do programa SAEG versão 7.0 (1997), e as médias comparadas pelo teste Tukey a $0,05 \%$ de probabilidade.

Tabela 1 - Equações utilizadas para estimativa da composição em aminoácidos totais e coeficientes de digestibilidade 1 Table 1 - Equations used to predict the total amino acid compositions and values of digestible coefficients

\begin{tabular}{|c|c|c|}
\hline $\begin{array}{l}\text { Equaçao de regressão } \\
\text { Regression equation }\end{array}$ & $\mathrm{R}$ & $\begin{array}{c}\text { Coeficiente de digestibilidade (\%) } \\
\text { Digestible coeffficient }\end{array}$ \\
\hline \multicolumn{3}{|l|}{ Milho (Corn) } \\
\hline Metionina (Methionine) $(\%)=0,0170 \cdot \mathrm{PB}(\%)+0,033$ & 0,70 & 93 \\
\hline Met + Cist $($ Met + Cist $)(\%)=0,0283 \cdot \mathrm{PB}(\%)+0,129$ & 0,72 & 90 \\
\hline Lisina (Lysine) $(\%)=0,0186 \cdot \mathrm{PB}(\%)+0,079$ & 0,62 & 90 \\
\hline Treonina (Threonine) $(\%)=0,0326 \cdot \mathrm{PB}(\%)+0,030$ & 0,93 & 87 \\
\hline \multicolumn{3}{|l|}{ Farelo de soja (Soybean meal) } \\
\hline Metionina (Methionine) $(\%)=0,0141 \cdot \mathrm{PB}(\%)+0,017$ & 0,65 & 92 \\
\hline Met + Cis $($ Met + Cist $)(\%)=0,0263 \cdot \mathrm{PB}(\%)+0,147$ & 0,57 & 88 \\
\hline Lisina (Lysine) $(\%)=0,0644 . \mathrm{PB}(\%)-0,081$ & 0,78 & 90 \\
\hline Treonina $($ Threonine $)(\%)=0,0381 \cdot \mathrm{PB}(\%)+0,081$ & 0,81 & 89 \\
\hline \multicolumn{3}{|l|}{ Farelo de arroz (Rice bran) } \\
\hline Metionina (Methionine) $(\%)=0,0240 \cdot \mathrm{PB}(\%)-0,040$ & 0,94 & 85 \\
\hline Met + Cis $($ Met + Cist $)(\%)=0,0425 \cdot \mathrm{PB}(\%)+0,004$ & 0,97 & 83 \\
\hline Lisina $($ Lysine $)(\%)=0,0446 \cdot \mathrm{PB}(\%)+0,022$ & 0,96 & 80 \\
\hline Treonina (Threonine) $(\%)=0,0359 \cdot \mathrm{PB}(\%)+0,031$ & 0,95 & 80 \\
\hline
\end{tabular}

${ }^{1}$ Equações e coeficientes de digestibilidade apresentados nas Tabelas da Degussa (1996).

${ }^{1}$ Equations and digestible coefficients showed in Tables of Degussa (1996). 
Tabela 2 - Composição percentual e níveis de aminoácidos calculados das rações Table 2 - Ingredient composition and calculated amino acid levels of the diets

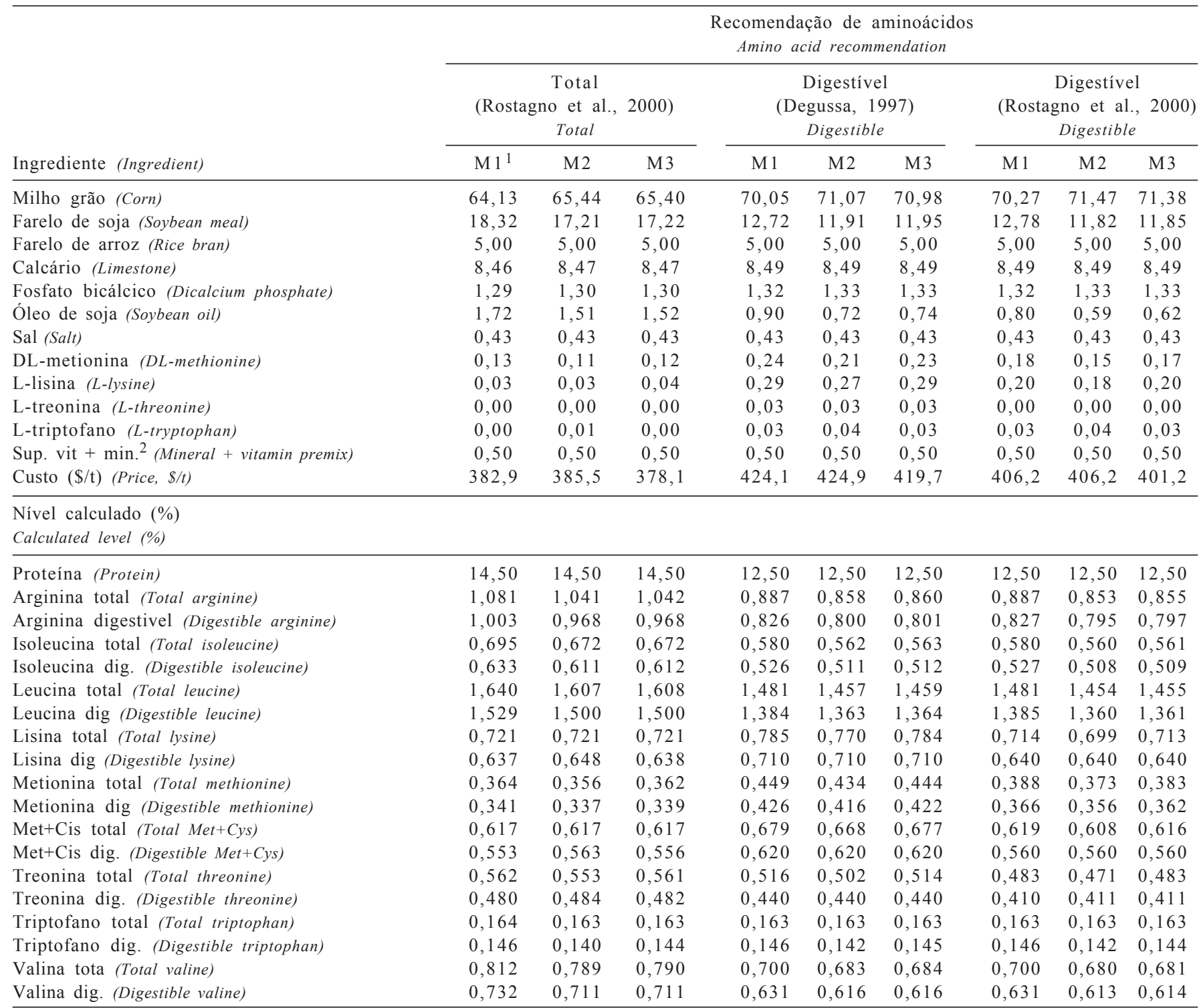

1 M1 = Tabelas brasileiras; $M 2$ = equações de predição e M3 = fator de aminoácido.

2* Enriquecimento por kg de ração: Vit. A - 8.000 Ul; Vit. D3 - 2.000 Ul; Vit. E - 50 mg; Vit. K3 - 3 mg; Vit. B1 - 1,5 mg; Vit. B2 - 4 mg; Vit. B6 - $0,12 \mathrm{mg}$ Vit. B12 - $15 \mathrm{mcg}$; Ácido fólico - 0,6 mg; Ácido pantotênico $10 \mathrm{mg}$; Niacina - $30 \mathrm{mg}$; Biotina - 0,1 mg; Colina - $300 \mathrm{mg}$; Ferro - $50 \mathrm{mg}$; Cobre - $10 \mathrm{mg}$; Zinco - $70 \mathrm{mg}$; Manganês - $100 \mathrm{mg}$; lodo $-1 \mathrm{mg}$; Selênio - 0,3 mg; Antioxidante (BHT) - $50 \mathrm{mg}$.

$1 \quad M 1=$ Brazilian tables; $M 2=$ prediction equations and $M 3=$ amino acid factor.

2* Perkg of diet: Vit. A-8.000 Ul; Vit. D3-2.000 Ul; Vit. E- 50 mg; Vit. K3-3 mg; Vit. B1-1,5 mg; Vit. B2-4 mg; Vit. B6-0,12 mg, Vit. B12-15 mcg; Folacin-0,6 mg; Pantothenic acid $10 \mathrm{mg}$; Niacine-30 mg; Biotine - 0,1 mg; Choline- $300 \mathrm{mg}$; Iron-50 mg; Copper-10 mg; Zinc- $70 \mathrm{mg}$; Manganese - $100 \mathrm{mg}$; lodine - $1 \mathrm{mg}$; Selenium-0,3 mg; Antioxidant(BHT) - $50 \mathrm{mg}$.

\section{Resultados e Discussão}

Não se observou significância para as interações métodos de estimativa da composição de aminoácidos dos alimentos $\mathrm{x}$ recomendações de aminoácidos para os parâmetros de desempenho (Tabela 3 ). O efeito isolado dos métodos de estimativa da composição dos alimentos em aminoácidos foi observado apenas para conversão alimen$\operatorname{tar}(\mathrm{P}<0,05)$. As rações formuladas com a aplicação do fator de aminoácidos (Método 3) resultaram em pior conversão alimentar em relação àquelas formuladas com base nos valores de aminoácidos dos alimentos (Método 1).

Observou-se efeito significativo das diferentes recomendações de aminoácidos sobre todos os parâmetros de desempenho avaliados $(\mathrm{P}<0,01)$, de modo que as rações formuladas com base nas recomendações de aminoácidos totais proporcionaram melhores resultados que aquelas formuladas com base nas duas recomendações de aminoácidos digestíveis, as quais promoveram desempenho semelhante. 
Tabela 3 - Desempenho de poedeiras comerciais alimentadas com rações formuladas com base em três métodos de estimativa da composição em aminoácidos dos ingredientes e três recomendações de aminoácidos no período de 27 a 42 semanas de idade

Table 3 - Performance of laying hens feeding diets formulated with three methods of estimate of amino acid ingredient composition and three amino acid recommendations

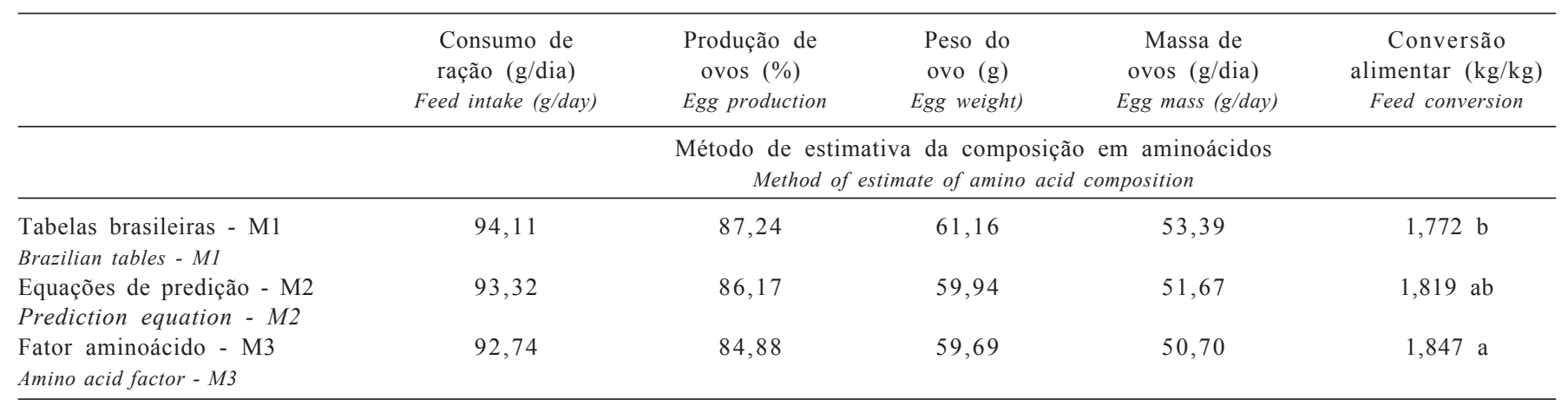

Amino acid factor - M3

Recomendação de aminoácidos ${ }^{1}$

Effect of the amino acid recommendations

\begin{tabular}{|c|c|c|c|c|c|}
\hline AAT-Rostagno & 98,79 a & 92,89 a & $61,60 \mathrm{a}$ & 57,18 a & $1,730 \mathrm{~b}$ \\
\hline AAD-Degussa & $90,17 \mathrm{~b}$ & $83,03 \mathrm{~b}$ & $59,50 \mathrm{~b}$ & $49,42 \mathrm{~b}$ & 1,836 a \\
\hline \multirow[t]{2}{*}{ AAD-Rostagno } & $91,22 \mathrm{~b}$ & $82,37 \mathrm{~b}$ & $59,69 \mathrm{~b}$ & $49,15 \mathrm{~b}$ & $1,873 \mathrm{a}$ \\
\hline & \multicolumn{5}{|c|}{$\begin{array}{c}\text { Valores de } \mathrm{F} \\
F \text { values }\end{array}$} \\
\hline Métodos (M) & $0,29 \mathrm{NS}$ & $0,70 \mathrm{NS}$ & $2,38 \mathrm{NS}$ & $2,08 \mathrm{NS}$ & $4,56 *$ \\
\hline \multicolumn{6}{|l|}{ Method } \\
\hline Recomendações & $13,87 * *$ & $16,53 * *$ & $5,16 * *$ & $23,28 * *$ & $17,43 * *$ \\
\hline \multicolumn{6}{|l|}{ Recommendation (R) } \\
\hline $\mathrm{M} \times \mathrm{R}$ & $1,32 \mathrm{NS}$ & $0,91 \mathrm{NS}$ & $1,94 \mathrm{NS}$ & $1,08 \mathrm{NS}$ & $1,58 \mathrm{NS}$ \\
\hline CV (\%) & 4,05 & 5,05 & 2,55 & 5,46 & 2,93 \\
\hline
\end{tabular}

${ }^{1}$ AAT - Rostagno = aminoácidos totais preconizados por Rostagno et al. (2000); AAD-Degussa = aminoácidos digestíveis preconizados por Degussa (1997) e AAD - Rostagno = aminoácidos digestíveis preconizados por Rostagno et al. (2000).

Para cada fator, letras distintas na coluna diferem $(P<0,05)$ pelo teste de Tukey.

${ }^{1}$ AAT-Rostagno = total amino acid indicated by Rostagno et al. (2000); AAD-Degussa = digestible amino acid indicated in Degussa (1997) e AAD-Rostagno = digestible amino acid indicated by Rostagno et al. (2000).

For each factor different letters in the column differ $(P<0.05)$ by Tukey test.

${ }^{* *}=(\mathrm{P}<0,01) ;^{*}=(\mathrm{P}<0,05) ; \mathrm{NS}=$ não-significativo (not significant) $(\mathrm{P}>0,05)$.

Casartelli (2004), avaliando diferentes recomendações de aminoácidos para poedeiras comerciais, também não encontrou diferenças expressivas entre as recomendações de aminoácidos digestíveis (Rostagno et al., 2000 vs. Degussa, 1997) ou entre as de aminoácidos totais (Rostagno et al., 2000 vs. NRC, 1994). Entretanto, quando comparou recomendações de aminoácidos totais e digestíveis, verificou diferenças evidentes, com o pior desempenho para as rações formuladas com base em aminoácidos digestíveis, o que contraria estudos anteriores (Wangen, 1993; Rostagno et al., 1995; Fernandez et al., 1995; Khatun et al., 1999). Casartelli (2004) atribuiu o pior desempenho das aves alimentadas com rações formuladas com base em aminoácidos digestíveis $(12,5 \%$ PB) à deficiência em nitrogênio para a síntese de aminoácidos não essenciais e de outros essencias, como arginina, isoleucina, leucina e valina, cujo suprimento ficou abaixo das exigências das aves.

Camps \& Edghill (1999) observaram que a redução nos níveis de PB (16 a 12\% PB) comprometeu a produção, a massa de ovos e a conversão alimentar de poedeiras. Segundo
Leeson \& Summers (2001), apesar de a diminuição no nível de proteína das rações para poedeiras representar uma estratégia para diminuição no impacto ambiental das excretas, geralmente promove a diminuição da massa de ovos, como conseqüência da redução no tamanho do ovo, o que ocorreu também neste trabalho (Tabelas 2 e 3 ).

Como neste estudo, Silva et al. (2000) não observaram os benefícios da formulação com base na digestibilidade de aminoácidos e sugeriram que a utilização de dados de digestibilidade obtidos com galos cecectomizados não seja o método mais correto para estudos com poedeiras. Entretanto, esses autores não observaram redução no desempenho de aves alimentadas com rações à base de aminoácidos digestíveis.

$\mathrm{Na}$ Tabela 4 observa-se que, para a unidade Haugh e os parâmetros de qualidade externa dos ovos, não ocorreram interações significativas entre os métodos de estimativa da composição de aminoácidos dos alimentos e as recomendações de aminoácidos. O efeito isolado dos métodos de estimativa da composição dos alimentos em aminoácidos ou das recomendações de aminoácidos também não foi 
observado ( $\mathrm{P}>0,05)$. Casartelli (2004) avaliou diferentes recomendações de aminoácidos totais e digestíveis e também não encontrou diferenças para os parâmetros de qualidade interna ou externa dos ovos.
A formulação das rações considerando diferentes composições de aminoácidos para ingredientes determinou pequenas variações no custo por tonelada de ração (Tabela 5). Entretanto, quando consideradas as diferentes recomendações

Tabela 4 - Qualidade de ovos de poedeiras comerciais alimentadas com rações formuladas com base em três métodos de estimativa da composição de ingredientes em aminoácidos e três recomendações de aminoácidos

Table 4 - Egg quality of laying hens feeding diets formulated with three methods of estimate of amino acid ingredient composition and three amino acid recommendations

\begin{tabular}{ccc}
\hline Unidade haugh & Gravidade específica $(\mathrm{g} / \mathrm{mL})$ & Porcentagem de casca \\
Haugh unit & Specific gravity & Shell percentage \\
\hline
\end{tabular}

Método de estimativa da composição em aminoácidos Method of estimate of amino acid composition

\begin{tabular}{|c|c|c|c|c|}
\hline $\begin{array}{l}\text { Tabelas brasileiras - M1 } \\
\text { Brazilian tables - M1 }\end{array}$ & 95,56 & 1,0895 & 9,65 & 395 \\
\hline Equações de predição - M2 & 96,04 & 1,0898 & 9,69 & 386 \\
\hline $\begin{array}{l}\text { Prediction equation - M2 } \\
\text { Fator aminoácido - M3 }\end{array}$ & & & & \\
\hline Fator aminoácido - M3 & 95,55 & 1,0890 & 9,57 & 86 \\
\hline
\end{tabular}

Amino acid factor - M3

Recomendação de aminoácidos ${ }^{1}$

Effect of amino acid recommendations

\begin{tabular}{|c|c|c|c|c|}
\hline AAT-Rostagno & 95,60 & 1,0898 & 9,56 & 392 \\
\hline AAD-Degussa & 95,35 & 1,0897 & 9,74 & 387 \\
\hline AAD-Rostagno & 95,89 & 1,0888 & 9,61 & 385 \\
\hline \multicolumn{5}{|l|}{ Valores de F } \\
\hline \multicolumn{5}{|l|}{$F$ values } \\
\hline Métodos (M) & $1,24 \mathrm{NS}$ & $1,05 \mathrm{NS}$ & $0,54 \mathrm{NS}$ & $5,87 \mathrm{NS}$ \\
\hline \multicolumn{5}{|l|}{ Method } \\
\hline Recomendações (R) & $1,26 \mathrm{NS}$ & $1,83 \mathrm{NS}$ & $1,36 \mathrm{NS}$ & $2,12 \mathrm{NS}$ \\
\hline \multicolumn{5}{|l|}{ Recommendation } \\
\hline $\mathrm{M} \times \mathrm{R}$ & $0,48 \mathrm{NS}$ & $0,81 \mathrm{NS}$ & $2,12 \mathrm{NS}$ & $1,04 \mathrm{NS}$ \\
\hline $\mathrm{CV}(\%)$ & 1,25 & 0,11 & 2,48 & 1,93 \\
\hline
\end{tabular}

${ }_{1}^{1}$ AAT- Rostagno = aminoácidos totais preconizados por Rostagno et al. (2000); AAD-Degussa = aminoácidos digestíveis preconizados por Degussa (1997) e AAD-Rostagno = aminoácidos digestíveis preconizados por Rostagno et al. (2000).

1 AAT-Rostagno = total amino acid indicated by Rostagno et al. (2000); AAD-Degussa = digestible amino acid indicated in Degussa (1997) e AAD-Rostagno = digestible amino acid indicated by Rostagno et al. (2000).

$\mathrm{NS}=$ não significativo (not significant) $(P>0,05)$.

Tabela 5 - Parâmetros de custo de rações formuladas com base em três métodos de estimativa da composição de ingredientes em aminoácidos (M) e duas recomendações $(R)$ de aminoácidos totais

Table 5 - Parameters of production cost for laying hens feeding diets formulated with three methods of estimate of amino acid ingredient composition and three amino acid recommendations

\begin{tabular}{|c|c|c|c|}
\hline & $\begin{array}{c}\text { Custo da ração }(\mathrm{R} \$ / \mathrm{t}) \\
\text { Diet cost }\end{array}$ & $\begin{array}{c}\text { Custo } / \mathrm{kg} \text { de ovo }(\mathrm{R} \$ / \mathrm{kg}) \\
\text { Egg cost } / \mathrm{kg}\end{array}$ & $\begin{array}{c}\text { Custo/dúzia de ovos (R\$/dúzia) } \\
\text { Cost/dozen }\end{array}$ \\
\hline & \multicolumn{3}{|c|}{$\begin{array}{l}\text { Método de estimativa da composição em aminoácidos } \\
\text { Method of estimate of amino acid composition }\end{array}$} \\
\hline $\begin{array}{l}\text { Tabelas brasileiras - M1 } \\
\text { Brazilian tables - M1 }\end{array}$ & 404,4 & 0,72 & 0,52 \\
\hline $\begin{array}{l}\text { Equações de predição - M2 } \\
\text { Prediction equation - M2 }\end{array}$ & 405,5 & 0,74 & 0,52 \\
\hline $\begin{array}{l}\text { Fator aminoácido - M3 } \\
\text { Amino acid factor - } M 3\end{array}$ & 399,7 & 0,74 & 0,52 \\
\hline
\end{tabular}

Amino acid factor - M3

Recomendação de aminoácidos ${ }^{1}$

Effect of the amino acid recommendations

\begin{tabular}{llll}
\hline AAT - Rostagno & 382,2 & 0,66 & 0,49 \\
AAD - Degussa & 422,9 & 0,78 & 0,54 \\
AAD - Rostagno & 404,5 & 0,76 & 0,53 \\
\hline
\end{tabular}

${ }^{1}$ AAT-Rostagno = aminoácidos totais preconizados por Rostagno et al. (2000); AAD-Degussa = aminoácidos digestíveis preconizados em Degussa (1997) e AAD-Rostagno = aminoácidos digestíveis preconizados por Rostagno et al. (2000).

${ }^{1}$ AAT-Rostagno = total amino acid indicated by Rostagno et al. (2000); AAD-Degussa = digestible amino acid indicated in Degussa (1997) e AAD-Rostagno = digestible amino acid indicated by Rostagno et al. (2000). 
de aminoácidos, essas variações foram bastante expressivas. Os diferentes métodos de estimativa da composição em aminoácidos dos ingredientes determinaram custos de produção de ovos bastante semelhantes. Constatou-se que as recomendações de aminoácidos totais resultaram em menores custos por quilo e por dúzia de ovos produzidos, ao contrário do observado com as recomendações de aminoácidos digestíveis.

A utilização das recomendações de aminoácidos digestíveis das tabelas da Degussa (1997) incidiu em maior custo por tonelada de ração, em decorrência da maior necessidade de utilização de aminoácidos sintéticos para atendimento dos níveis recomendados.

\section{Conclusões}

As diferentes formas de obtenção da estimativa da composição de aminoácidos em ingredientes não determinaram diferenças expressivas nos parâmetros avaliados, mas a utilização dos valores apresentados nas tabelas brasileiras indicou melhor precisão. As recomendações de aminoácidos totais resultaram em melhor desempenho em relação às de aminoácidos digestíveis.

\section{Literatura Citada}

ARAÚJO, L.F.; JUNQUEIRA, O.M.; ARAÚJO, C.S.S. et al. Different criteria of feed formulation for broilers aged 43 to 49 days. Revista Brasileira de Ciência Avícola, v.6, n.1, p.61-64, 2004 .

BELLAVER C.; BRUM, P.A.R.; LIMA, G.M.M. et al. Substituição parcial do farelo de soja pela farinha de vísceras de aves em dietas balanceadas com base na proteína e em aminoácidos totais ou digestíveis para frangos de corte. Revista Brasileira de Ciência Avícola, v.3, n.3, p.233-240, 2001.

CAMPS, D.M.; EDGHILL E. Niveles de proteina en dietas para ponedoras. Revista Cubana de Ciencia Avicola, v.23, n.1, p. 35-40, 1999

CASARTELLI, E.M. Alimentos alternativos ao milho e farelo de soja em rações de poedeiras comerciais formuladas com base em aminoácidos totais e digestíveis. Jaboticabal, 2004. 85p. Dissertação (Mestrado em Zootecnia) - Faculdade de Ciências Agrárias e Veterinárias - Universidade Estadual Paulista, 2004.

DALE, N. Formulación de dietas sobre la base de disponibilidad de aminoácidos. Avicultura Profesional, v.9, n.3, p.120-122, 1992.

DEGUSSA, 1996 - Amino acid composition of the feedstuffs. Applied Technology Feed additives. Hanau

DEGUSSA, 1997 - Amino acid requirements for poultry. Feed formulation Guide. Hanau.
DOULGLAS, M.W.; PARSONS, C.M. Dietary formulation with rendered spent hen meals on a total amino acid versus a digestible amino acid basis. Poultry Science, v.78, n.4, p.556-560, 1999.

FARREL, D.J., MANNION, P.F., PEREZ-MALDONADO, R.A.A comparison of total and digestible amino acids in diets for broilers and layers. Animal Feed Science and Technology, v. 82, p.131-142, 1999 .

FERNÁNDEZ, S.R.; ZHANG, Y.; PARSONS, C.M. Dietary formulation with cottonsed meal on a total amino acid versus a digestible amino acid basis. Poultry Science, v.74, p.1168 $1179,1995$.

KHATUN, A., ALI, M.A., DINGLE, J.G. Comparison of the nutritive value for laying hens of diets containing azolla (Azolla pinnata) based on formulation using digestible protein and digestible amino acid versus total protein and total amino acid. Animal Feed Science and Technology, v.81, p.43-56, 1999.

LEESON, S.; SUMMERS, J. D. Nutrition of the chicken. 4.ed, Ghelph: University Books, 2001. 591p.

MAIORKA, A.; DAHLKE, F.; SANTINE, E. et al. et al. Effect of energy levels of diets formulated on total or digestible amino acid basis on broiler performance. Brazilian Journal of Poultry Science, v.6, n.2, p.87-91, 2004.

NATIONAL RESEARCH COUNCIL - NRC. Nutrient requirements of the poultry. Washington: Committee on Animal Nutrition. Subcommittee on Poultry Nutrition. 9.ed 1994. $155 \mathrm{p}$.

ROSTAGNO, H.S.; ALBINO, L.F.T.; DONZELE, J.L. et al. Composição de alimentos e exigências nutricionais de aves e suínos: Tabelas Brasileiras, Viçosa, MG: Universidade Federal de Viçosa, 2000. 141p.

ROSTAGNO, H.S.; PUPA, J.M.R.; PACK, M. Diet formulation for broilers based on total versus digestible amino acid. Journal Applied Poultry Research, v.4, p.293-299, 1995.

UNIVERSIDADE FEDERAL DE VIÇOSA - UFV. SAEG - Sistema para análises estatísticas e genéticas. versão 7.0. Viçosa, MG: Fundação Arthur Bernardes, 1997.

SIBBALD, I.R. Estimation of bioavailable amino acids in feedingstuffs for poultry and pigs: a review with emphasis on balance experiments. Canadian Journal of Animal Science, v.67, n.2, p.221-300, 1987

SILVA, J.H.V.; MUKAMI, F.; ALBINO, L.F.T. Uso de rações à base de aminoácidos digestíveis para poedeiras. Revista Brasileira de Zootecnia, v.29, n.5, p.1446-1451, 2000.

SWICK, R. Recent advances in amino acid formulation. In: NEW DEVELOPMENTS IN FEED AND POULTRY TECHNOLOGY TECHNICAL SYMPOSIA, 1992, Sidney. Proceedings... Sidney: Novus International, 1992. p.69-81.

WANG, X.; PARSONS, M. Dietary formulation with meat and bone meal on a total versus a digestible amino acid basis. Poultry Science, v.77, n.7, p.1010-1015, 1998

WANGEN, X. A study of diet formulation for layers on available amino acid basis. Acta Veterinária et Zootechnia Sinica, v.24, n.4, p.319-325, 1993. 